\title{
How far does VLE self-directed study facilitate improvements in written, practical and overall assessment results? Sports Therapy \\ case study
}

Kristian Weaver $^{\mathrm{a} *}$, Daniel Brown ${ }^{\mathrm{a}}$, Dr John Bostock ${ }^{\mathrm{b}}$, Dr Julie Kirby ${ }^{\mathrm{c}}$

${ }^{a}$ Department of Sport and Physical Activity, Edge Hill University, Ormskirk, United Kingdom;

${ }^{b}$ Centre for Teaching and Learning, Edge Hill University, Ormskirk, United Kingdom; ${ }^{c}$ Faculty

of Health and Social Care, Edge Hill University, Ormskirk, United Kingdom

\section{Contact details of corresponding author:}

Kristian Weaver (ORCID: https://orcid.org/0000-0003-4086-8579)

Edge Hill University, St Helens Road, Ormskirk, Lancashire, L394QP, UK

Telephone number 01695575171

\begin{abstract}
It is unclear whether engagement with Virtual Learning Environment (VLE) self-directed study can enhance the learning process and augment academic achievement. As such, the current study aims to investigate the relationship between VLE self-directed study provision in a Sports Therapy module and subsequent academic summative assessment success. The sample was comprised of 232 undergraduate BSc (Hons) Sports Therapy students (113 male, 119 female) across three separate student cohorts $(2015,2016,2017)$. Each cohort was provided with differing VLE self-directed study. Analysis was conducted on its effect on achievement during both practical and written modes of summative assessment. The results of the current study
\end{abstract}

\footnotetext{
*Email: weaverk@edgehill.ac.uk
} 
suggest that while digital technology did not attenuate academic achievement, accurate alignment to the intended learning outcomes and summative assessments may be required for its successful integration into Higher Education pedagogy.

Keywords: Self-directed study, Pedagogy, Sports Therapy, Assessment, Virtual Learning Environment.

\section{Introduction}

The use of summative assessments is one component that has remained constant across generations in the dynamic environment that comprises Higher Education (HE). The forms of assessment continue to enable the quantification of academic performance and subsequent degree award classifications (Merriam, 2001; Gibbs \& Simpson, 2004; Edge Hill University, 2017). In comparison to previous generations, however, the student population of today's HE environment is one that is increasingly driven by the engagement with VLEs (Gurung \& Rutledge, 2014; Rashid \& Asghar, 2016). As such, the inclusion of online self-directed study may facilitate/enhance the learning process and subsequently augment students' achievement in the discipline of Sports Therapy, whereby both practical and written summative assessments are required (Rashid \& Asghar, 2016).

The art and science of helping adults learn (andragogy) is distinguished from more traditional pedagogies; with one key assumption being that the adult learner is self-motivated and engaged in driving their own independent learning (Merriam, 2001). This has previously been critiqued due to the uncertainty of the distinctions between the adult and child learner, first scrutinised by Knowles in the 1970's (Hartree, 1984). Nevertheless, it is plausible that the use of VLEs within adult teaching and learning could provide a unique opportunity for teaching-, peer-, and self-directed learning (Forgrave, 2002; Barnes, Marateo, \& Ferris, 2007; 
Lombardozzi, 2016). In recent times, the development of VLEs has provided essential learning tools that complement taught classroom sessions by providing students with the ability to access and synthesise content within their own time (Hartley, Woods \& Pill, 2005; Race \& Pickford, 2007). This has relevance within Sports Therapy teaching whereby traditional lectures are accompanied by seminar and practical sessions that contain information that may need to be digested by the student external to the face to face environment. The ability to access such content is seemingly imperative, with reports that $75.8 \%$ of an undergraduate student cohort regularly access study-related content online with the use of a VLE, and a further $94.7 \%$ considering this ability to access learning material using a VLE as an important contributor to their eventual success whilst at university (Edge Hill University, 2012). In addition, the autonomous nature of practising and learning as a Sports Therapist relies upon the core principles of andragogy.

The use of online self-directed study via the VLE is an important pedagogical and educational tool has been linked with significant improvements in student motivation, engagement, long-term knowledge retention and subsequent success during the completion of summative academic assessments (Trimmel \& Bachmann, 2004; Fonseca, Marti, Redondon, Navarro \& Sánchez, 2014). In contrast, online resource use in teaching and learning has been reported to potentially attenuate learner engagement through distraction away from the taught content (Paretta \& Catalano, 2013; Gurung \& Rutledge,2014). More recently, VLE use amongst undergraduate university students was reported to positively predict self-directed learning $(\beta=0.32, P<0.01)$ and student engagement $(\beta=0.31, P<0.01)$. It could be suggested that, while not all modes of digital technology are particularly suited to HE and curriculum design, if used/integrated appropriately, academic performance could potentially be improved.

This study aims to provide further contributions to the continued interest in VLEs, defined as the integration of technology into pedagogical practices in an attempt to 
facilitate/enhance the learning process (Goodyear \& Retalis, 2010). The secondary aim is to investigate the use of online self-directed study and its efficacy regarding academic achievement in both practical and examination modes of summative assessment in the module of Anatomy and Physiology on the BSc (Hons) Sports Therapy degree programme. Knowledge gained from conducting such research will enhance understanding of such relationships and may be used to inform future teaching practice.

Research question:

How far does VLE self-directed study facilitate improvements in written, practical and overall assessment results?

\section{Methodology}

\section{Participants}

The current investigation was a retrospective case study. The sample was comprised of 232 undergraduate students (113 male, 119 female) across three separate student cohorts on the BSc (Hons) Sports Therapy degree programme (2015 cohort: $n=80$ (38 male, 42 female); 2016 cohort: $n=80$ (35 male, 45 female); 2017 cohort: $n=72$ (40 male, 32 female)). Using the VLE, each retrospective cohort had been provided with different modes of online selfdirected study, with provision provided/adapted based upon feedback obtained from previous ones. Students could access the VLE on the electronic device of their choosing. Each cohort had received directed reading to supplement the taught content; however, the 2016 cohort were also provided with 7 narrated myology lecture slides (estimated length 30 minutes each) for audible and visual consumption and 9 open answer online quizzes (estimated time to complete 20 minutes each) which they could complete at any time during the semester. In comparison, the 2017 cohort were provided with 7 narrated myology lecture slides (length 30 minutes each) 
for audible and visual consumption and 9 multiple-choice online quizzes (estimated time to complete 10 minutes each) which they could complete at any time during the semester. Specific inclusion criteria are described below; if a participant did not meet each of these criteria their data set was subsequently removed from further analysis.

\section{Inclusion criteria}

Participants had

- completed the 'Introduction to Anatomy and Physiology' module practical examination and in-class test between 2015 and 2018 .

- engaged with at least one of the online narrated lectures and in at least one online open answer/multiple-choice tests in the 2016 and 2017 cohorts.

- engaged in the 2016 and 2017 cohorts.

- attended at least $75 \%$ of the modules taught contact hours.

- met the University's entry requirements (consistent UCAS point entry) for the BSc (Hons) Sports Therapy programme.

The in-class test consisted of short answer questions on the taught Anatomy and Physiology material and marked by an individual module leader, moderated and then processed according to the University's quality assurance guidelines. The marking criteria were unambiguous and required clear, concise answers to be provided by the student.

Practical examinations were conducted on the joints of the body (upper limb, lower limb and spinal) whereby students were required to verbalise, locate and demonstrate movements, muscles, origins, insertions and actions; for which the student was marked via unambiguous criteria. Examinations were marked and moderated according to the University's quality assurance guidelines. 


\section{Ethical issues}

Ethical approval was obtained from the University Ethics Committee prior to study onset. This retrospective Sports Therapy case study involved the convenience sampling of Level 4 BSc (Hons) Sport Therapy student cohorts that had completed the 'Introduction to Anatomy and Physiology' module. Data analysis was conducted in accordance with the University's information strategy regarding the use of student data (Edge Hill University, 2016). Participant data was protected in accordance with the Data Protection Act of 2003 and the General Data Protection Regulation of 2018.

\section{Data collection}

A parallel-groups design was employed. Participants were manually allocated to one of three cohorts based upon their year of enrolment on the BSc (Hons) Sports Therapy degree programme and the Level 4 'Introduction to Anatomy and Physiology' module (2015 vs. 2016 vs. 2017). Prior to analysis, data for participant attendance was collected from the Department's online log-system used for the monitoring of student attendance, with those students who attended less than $75 \%$ of sessions subsequently excluded. Assessment performance data (written in-class test, practical examination and overall module grades) for each cohort/group was also obtained from the Department, with online self-directed study engagement also assessed via the individual logs created on the VLE.

\section{Statistical analysis}


Normality, homogeneity and sphericity of the data set was first determined with the use of the following; a Shapiro-Wilk test for normality, Levene's test for homogeneity of variances, and finally Mauchly's test of sphericity. As each assumption was met, assessment data/grades (written in-class test, practical examination and overall grade) between the three cohorts were analysed using a one-way analysis of variance (ANOVA), with appropriate post-hoc analysis conducted if a significant effect was reported. Effect sizes were also calculated using Cohen's d when necessary. In the 2016 and 2017 cohorts, Pearson's correlational analysis (r) was then conducted to elucidate whether a relationship exists between the scores/grades achieved during the self-directed online open answer and multiple-choice tests and the scores/grades subsequently achieved during the summative assessments completed throughout/at the end of the module (i.e. written in-class test, practical examination and overall module grade). The strength of each relationship was then categorised as either; very weak (0.00-0.19), weak (0.20$0.39)$, moderate (0.40-0.59), strong (0.60-0.79) and very strong (0.80-1.00) in accordance with previous literature (Hopkins, 2000). All values are displayed as mean \pm standard deviation unless otherwise stated, with statistical analysis conducted using a statistical software package (SPSS, version 24, Chicago, USA).

\section{Results}

Initial analysis comparing the 2015 cohort (receiving directed reading only) to both the 2016 and 2017 cohorts (receiving additional VLE self-directed study) reported no significant effect of VLE self-directed study provision on the mean score (\%) achieved during the written inclass test $(P=0.428)$, the practical examination $(P=0.619)$ or the overall module score $(P=$ $0.853)$. 
Insert table 1 about here

When comparing each cohort individually (2015 vs. 2016 vs. 2017), there was no significant effect of VLE self-directed study provision on either practical examination $(P=0.615)$ or overall module grades $(P=0.312)$. A significant main effect of cohort was, however, reported in regard to the written in-class test, with the 2016 cohort (open answer online quiz provision) achieving a significantly higher grade $(\%)$ in comparison to the 2015 cohort $(P=0.04, \mathrm{~d}=$ $0.39,95 \%$ confidence intervals $(\mathrm{CI}) 0.20-10.60)$ and the 2017 cohort $(P=0.001, \mathrm{~d}=0.58$, 95\% CI 2.80 to 13.49 ), respectively (Figure 1 ).

Insert Figure 1 near here

Pearson's correlational analysis also reported a significant but weak relationship in the 2016 cohort between the total scores achieved during the VLE self-directed open answer quizzes and the resultant scores achieved during the written in-class test $(r=0.242, P=0.032)$, the practical examination $(r=0.281, P=0.012)$ and overall module grades $(r=0.284, P=$ 0.011). Interestingly, the 2017 cohort total scores achieved in the VLE self-directed multiplechoice (closed answer) quizzes were also significantly, but this time moderately, correlated to written in-class test grades $(r=0.479, P<0.001)$, practical examination grades $(r=0.463, \mathrm{P}$ $<0.001)$ and the overall module grades $(r=0.484, P<0.001)$, respectively. Relationships between VLE self-directed open answer and multiple-choice quiz scores in the 2016 and 2017 cohorts are depicted graphically in Figures 2 and 3 below.

Insert Figure 2 near here

Insert Figure 3 near here 


\section{Discussion}

\section{Teaching theory application}

Self-directed study is entwined with the teaching theories of humanism, progressivism and existentialism; a key theme being the use of a student-centred approach whereby students are empowered to take control of their own learning required by autonomous Sports Therapy practitioners (Onurkan Aliusta \& Özer, 2016). Such an approach is thought to be beneficial for professions whereby autonomy, problem-solving and reflection are required (Assor, Kaplan, \& Roth, 2002). Using a self-directed learning approach alongside the delivery of taught material can enable students to develop strategies for their own learning, fitting into the progressivist teaching theory first described by Rousseau and then further expanded by Dewey in the $18^{\text {th }}$ and $19^{\text {th }}$ centuries (O'Sullivan, 2004).

Although there was an increasing amount of VLE self-directed study support in the module, there were no significant differences between scores for the practical assessment $(P=$ $0.615)$ or the overall module grades $(P=0.312)$. The results from this study directly contrast the philosophy of existentialism which implies that additional information and self-directed study should empower a student and influence their learning (Malik \& Akhter, 2013). There is a need to distinguish the rhetoric of adult education from its rationale and empirical base which asserts that in everyday life, adults are basically self-directed and that this is rooted in our constitutional make up. It also asserts that self-development is an inexorable process towards higher levels of existence; and finally, that adult learning is fundamentally (and necessarily) different from child learning.

Notably in this study, the entry requirements onto the degree programme remained consistent throughout the recruitment process (UCAS points), however, the potential changes in qualifying courses were unaccounted for. Since the Dearing Report in 1997, there has been 
a change towards more flexible curricula, learning and provision which can be facilitated with enhancements in technology (Bostock, 2018). This calls into question the role of the educator in trying to establish aspects that students value including real-life examples, demonstrating the depth of understanding required for good marks, assessing progress, encouraging effort, sustaining attention and allowing for peer learning opportunities (Dascalu, et al. 2015; Vuopala, Hyvönen \& Järvelä, 2016; Bostock 2018). The theory of humanism describes students being empowered, however, in the VLE it is increasingly difficult to obtain meaningful information for students who are independent (Khatib \& Hamidi, 2013; Dascalu et al. 2015). 'As the physical presence of the lecturer diminishes, the more sophisticated resources must become to maintain quality of dialogue and interaction, the more flexible and autonomous must the students become in order to cope and manage this change and of course the context of learning will begin to vary as the student responds' - Bostock (2018, p.14).

Despite there being no significant difference between cohorts in either practical assessment or overall module grades, there was a significant effect in regard to the in-class test, with the 2016 cohort achieving a significantly higher mean grade in comparison to both the $2015(P=0.04)$ and 2017 cohorts $(P=0.001)$, respectively. An increasing level of student support with a student-centred approach and VLE self-directed study has previously been touted as a potential way of improving student achievement (Trimmel \& Bachmann , 2004; Fonseca et al., 2014). Therefore, it may be argued that, despite consideration of specific teaching theory, constructive alignment to the requirements of the assessment must be considered for effective intervention. Constructive alignment was originally described by Tyler in 1949 stressing the requirement of relevant learning activities to obtain desired outcomes. In response to written module feedback from the 2016 student cohort, the VLE selfdirected study tasks for the 2017 cohort were changed from open answer questions to multiplechoice (closed) answer questions. However, misaligned tests of knowledge can be confusing 
for educators and does not provide the student with feedback that demonstrates their learning of the core content, which can be termed construct underrepresentation or construct irrelevant variance (Porter, Polikoff, Barghaus \& Yang, 2013). This may bring into question the ethical dilemma between the incorporation of teaching pedagogy and learning theory while responding positively to student feedback, which may require action that negatively impacts upon the TEF.

\section{The use of technology in the learning environment}

Within the HE environment there exists a generation of "digital natives" and the integration of digital technology in teaching and learning continues to receive a cascade of interest with a common expectation that engagement with VLEs enhances the learning process, consequently augmenting academic achievement in the process (Rogerson-Revell, 2015; Rashid \& Asghar, 2016). Currently, literature regarding the efficacy of VLEs is both confounding and equivocal. Positive effects are reported, with digital technology use linked with enhanced student engagement, academic achievement, intellectual development and career preparation $(\mathrm{Hu} \&$ Kuh, 2001; Trimmel \& Bachmann, 2004; Fonseca et al., 2014). On the other hand, it is reported to have no effect (Hunley et al., 2005), or a negative effect with high frequency use of digital technology considered a distraction and detrimental to the learning process (Paretta \& Catalano, 2013; Gurung \& Rutledge, 2014). The results of the study add to the inconsistencies present in this area. When VLE self-directed study was more closely aligned to the mode of assessment, a significant positive outcome was reported. This is apparent as, when open answer questions on the VLE were used in 2016, assessment grades during the in-class test, which also required students to answer open answer style questions, were significantly greater. This outcome is in support of previous literature, outlining that, although VLE learning technologies can augment the learning process, the simple provision of VLEs are not 
automatically predictive of beneficial learning outcomes; rather, online learning resources need to be constructively aligned to curriculum design and assessment practices in order to be effective (Biggs, 2003; Fung, 2004; Rogerson-Revell, 2015).

Further findings also allude to the presence of a significant weak-to-moderate relationship between the engagement with, and grades/scores received, in the online selfdirected quizzes, and achievement during the summative module assessments (i.e. in-class, practical and overall module grades; $r=0.242-0.484 ; P<0.05)$. Although weak-to-moderate, this finding is in support of previous literature whereby VLE integration had a positive indirect effect on academic performance (Rashid and Asghar 2016). Previously, VLE use has been suggested to provide learners with an opportunity to become self-directed, and therefore independent, in developing their own meaningful and deep learning experience (Barnes, Marateo \& Ferris, 2007). Caution is, however, required when generalising the findings from this study within Sports Therapy cohorts, with whom ongoing self-directed study is essential.

\section{Limitations and future research direction}

It is evident that although the present study provides a beneficial insight into the relationship/efficacy of VLE technology use and its effect on teaching and learning in HE, certain limitations and requirements are necessary. The present study is limited in its sample demographics, only recruiting participants from a Level 4 Sports Therapy module, on the same degree programme and from a single HE institution. Future research should therefore investigate whether a relationship between VLE technology and academic performance is similar, or in fact differs, across different subject areas, HE institutions and cultural climates. Further experimental design/analytical methodology capable of detecting different levels of engagement (i.e. time and effort afforded to VLE learning material) so that the relationship 
between VLE learning technology and academic achievement can be explored in more depth would be of value.

\section{Conclusion}

This study contributes to the ongoing contemporary issue within teaching and learning as to whether an engagement with VLEs can facilitate/enhance the learning process and subsequent success in summative academic assessments. Although current evidence remains equivocal, results of the present study suggest that the accurate 'alignment' of such technology to the intended learning outcomes and summative assessments may be of higher importance if it is going to be successfully integrated. Future research is, however, necessary to enable the development of a more robust and congruent conclusion in regard to the efficacy of technology enhanced learning.

\section{Disclosure statement}

The authors can confirm that there was no financial interest or benefit of conducting this study, however, the lead author was responsible for the delivery of the module across all three cohorts.

\section{Notes on contributors}

Kristian Weaver is a Lecturer in Sports Therapy in the Department of Sport and Physical Activity and lectures on a variety of modules on the Sports Therapy degree programme. Kristian is also member of the ethics committee for departmental staff research. 
Daniel Brown was a successful PhD student in the Department of Sport and Physical Activity at Edge Hill University where he taught on a variety of modules, primarily on the Sports Science degree programme.

John Bostock is a Senior Lecturer in Teaching and Learning Development at Edge Hill University. He is a National Teaching Fellow, Senior Fellow of SEDA and Principal Fellow of the HEA.

Julie Kirby is a Registered Nurse with experience of health service provision in national and international settings. She has a well-established clinical background in surgery and operating theatre nursing.

\section{References}

Assor, A., Kaplan, H., \& Roth, G. (2002). Choice is good, but relevance is excellent: Autonomy-enhancing and suppressing teacher behaviours predicting students' engagement in schoolwork. British Journal of Educational Psychology, 72, 261-78.

Barnes, K., Marateo, R. C., \& Ferris, S. P. (2007). Teaching and learning with the net generation. Innovate: Journal of Online Education, 3, 1-8.

Biggs, J. B. (2003). Teaching for quality learning at University. Second Edition. Buckingham: Society for Research into Higher Education: Open University Press.

Bostock, J. (2018). A model of flexible learning: Exploring interdependent relationships between students, lecturers, resources and contexts in virtual spaces. Journal of Perspectives in Applied Academic Practice, 6, 12-18.

Dascalu, M-I., Bodea, C-N., Moldoveanu, A., Mohora, A., Lytras, M., \& Ordoñez de Pablos, P. (2015). A recommender agent based on learning styles for better virtual collaborative learning experiences. Computers in Human Behavior, 45, 243-53. 
Edge Hill University. (2012). Headlines from the 4th EHU Student ELearning Survey. Lancashire: Edge Hill University.

Edge Hill University. (2016). Ethical guidance for undertaking research with Edge Hill University students. Lancashire: Edge Hill University.

Edge Hill University. (2017). Academic regulations 2017 / 18 for students commencing undergraduate and university awards". July. Lancashire: Edge Hill University.

Fonseca, D., Martí, N., Redondon, E., Navarro, I., \& Sánchez, A. (2014). Relationship between student profile, tool use, participation and academic performance with the use of augmented reality technology for visualized architecture models. Computers in Human Behavior, 31, 434-45.

Forgrave, K. E. (2002). Assistive technology: Empowering students with learning disabilities. Assistive Technology, 75, 122-126.

Fung, Y. Y. H. (2004). Collaborative online learning: Interaction patterns and limiting factors. Open Learning: The Journal of Open, Distance and e-Learning, 19, 35-49.

Gibbs, G., \& Simpson, C. (2004). Conditions under which assessment supports student learning. Learning and Teaching in Higher Education, 1, 3-31.

Goodyear, P., Retalis, S. (2010). Technology-enhanced learning. Rotterdam: Sense Publishers.

Gurung, B., \& Rutledge, D., (2014). Digital learners and the overlapping of their personal and educational digital engagement. Computers \& Education, 77, 91-100.

Hartley, P., Woods, A., \& Pill, M. (2005). Enhancing teaching in higher education: New approaches for improving student learning. New York: Routledge.

Hartree, A. (1984). Malcolm Knowles' Theory of Andragogy: A critique. International Journal of Lifelong Education, 3, 203-10.

Hopkins, W. G. (2000). Measures of reliability in sports medicine and science. Sports 
Medicine, $30,1-15$.

Hu, S., \& Kuh, G. D. (2001). Computing Experience and Good Practices in Undergraduate Education: Does the Degree of Campus "Wiredness" Matter? Education Policy Analysis Archives, 9 (49), 1-20.

Hunley, S. A., Evans, J. H., Delgado-Hachey, M., Krise, J., Rich, T., \& Schell, C. (2005). Adolescent computer use and academic achievement. Adolescence, 40, 307-18.

Khatib, M., \& Hamidi, H. (2013). Humanistic education: Concerns, implications and applications. Journal of Language Teaching and Research, 4, 45-51.

Lombardozzi, C. (2016). Challenges of learning in the flow of work: Scaffolding self-direction. International Journal of Human Resource Development: Practice, Policy \& Research, 1 , $27-39$.

Malik, G. M., \& Akhter, R. (2013). Existentialism and classroom practice. IOSR Journal Of Humanities And Social Science, 8, 2279-2837.

Merriam, S. B. (2001). Andragogy and self-directed learning: Pillars of adult learning theory. New Directions for Adult and Continuing Education, 89, 3-13.

O'Sullivan, M. (2004). The reconceptualisation of learner-centred approaches: A Namibian case study. International Journal of Educational Development, 24, 585-602.

Onurkan Aliusta, G., \& Özer, B. (2016). Student-Centred Learning (SCL): Roles changed. Teachers and Teaching, July, 1-14.

Paretta, L. T., \& Catalano, A. (2013). What students really do in the library: An observational study. Reference Librarian, 54, 157-67.

Porter, A., Polikoff, M. S., Barghaus, K. M., \& Yang, R. (2013). Constructing aligned assessments using automated test construction. Educational Researcher, 42, 415-23.

Race, P., \& Pickford, R. (2007). Making teaching work: "Teaching Smarter" in postcompulsory education. London: SAGE Publications. 
Rashid, T., \& Asghar, H. M. (2016). Technology use, self-directed learning, student engagement and academic performance: Examining the interrelations. Computers in Human Behavior, 63, 604-12.

Rogerson-Revell, P. (2015). Constructively aligning technologies with learning and assessment in a distance education master's programme. Distance Education, 36, 129-47.

Trimmel, M., \& Bachmann, J. (2004). Cognitive, social, motivational and health aspects of students in laptop classrooms. Journal of Computer Assisted Learning, 20, 151-58.

Vuopala, E., Hyvönen, P., \& Järvelä, S. (2016). Interaction forms in successful collaborative learning in virtual learning environments. Active Learning in Higher Education, 17, 2538. 